\title{
Candida precipitins in pregnant women: validity of the test systems used
}

\author{
VALERIE C. STANLEY AND ROSALINDE HURLEY \\ From the Bernhard Baron Memorial Research Laboratories, Queen Charlotte's Maternity Hospital, London
}

SYNOPSIS Sera from 200 pregnant women, with symptoms suggestive of vaginitis and harbouring yeast in the vagina, were examined for precipitating antibodies to three antigens of $C$. albicans, -7 using a gel double diffusion test. A high overall incidence of precipitin-positive sera (47.5\%) was found compared with an incidence of $18 \%$ in the unselected pregnant population previously studied (Stanley, Hurley, and Carroll 1972).

Using the clinicopathological criteria of Carroll, Hurley, and Stanley (1973); a final aetiological $\vec{c}$ diagnosis of $C$. albicans mycosis was reached in 75 cases and precipitins were demonstrated in $64 \%$. Forty-eight women harbouring $C$. albicans responded favourably to a single course of antifungal treatment, and probably had mycotic vaginitis. The incidence of precipitins in this group was $42 \%$. C. albicans was isolated from a further 55 of 62 patients, in whom the incidence of precipitins was $32 \%$.

'Booking' sera were investigated from 50 of the 200 women studied. Sixty-four per cent of women had symptoms of vaginitis at booking and $32 \%$ were precipitin positive. Twenty-eight per cent had precipitins on both occasions, and a further $24 \%$ acquired candida precipitins during pregnancy.

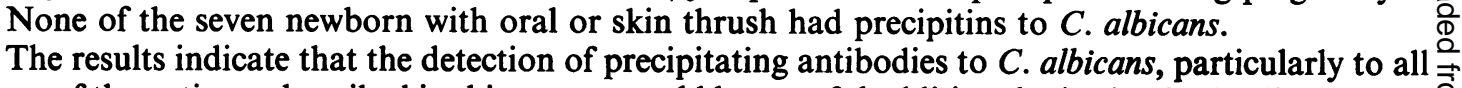
three of the antigens described in this paper, would be a useful additional criterion in the diagnosis of $\frac{\vec{O}}{3}$ candida vaginitis, particularly if the vaginitis were persistent, recurrent, or unresponsive to therapy. The sensitivity of the test system used was $64 \%$, and its specificity $87 \%$; as such, the test is valid and may be reasonably useful as a screening procedure.

In a previous study on an unselected pregnant population, Stanley, Hurley, and Carroll (1972) showed that precipitins to three antigens derived from Candida albicans, tested at two concentrations, occurred in $18 \%$ of sera from women booking at an antenatal clinic, and that these occurred significantly more frequently in women with probable mycotic vulvovaginitis. By analysis of prospectively recorded clinical data pertaining to this group, Carroll, Hurley, and Stanley (1973) established clinicopathological criteria on which the diagnosis of mycotic vulvovaginitis, or vaginitis, might be soundly based.

We now describe the incidence of candida precipitins in a further group of 200 pregnant women whose sera were selected for examination because of the probability of a high incidence of mycotic vaginitis amongst them. After analysis of the validity of the test systems used, we suggest that the tests in Received for publication 10 October 1973. their present form may be used as an adjunct to the diagnosis of candida vaginitis, or for population screening for early detection of disease.

\section{Materials and Methods}

Five $\mathrm{ml}$ clotted blood was requested from 200 women N who had been found, on laboratory examination of $N$ vaginal swabs sent for diagnosis of pregnancy $\mathbb{W}^{-}$ vaginitis, consecutively to be harbouring yeasts. Sera collected at 'booking' were also examined for 50 of these patients.

Subsequent swabs were examined from 96 women, $\stackrel{\mathbb{D}}{?}$ mainly from those who failed to respond promptly 0 or completely to treatment.

The methods used for examination of vaginal swabs and for isolation and identification of yeasts $\mathbb{D}$ are described elsewhere (Hurley, Leask, Faktor, and $\frac{}{\sigma}$ de Fonseka, 1973; Merritt and Hurley, 1972). 
The sera were tested for the presence of precipitating antibodies to $C$. albicans $A$ (LSHTM no. 3153). Gel double diffusion was carried out in $1 \%$ Oxoid Ionagar no. 2 buffered to $\mathrm{pH} 8.6$ with borate buffer, at a depth of $1 \mathrm{~mm}$. A pure cell wall mannan antigen $(1 \mathrm{mg} / \mathrm{ml})$, a culture filtrate antigen $(20 \mathrm{mg} / \mathrm{ml})$, and a Mickle-disintegrated cytoplasmic antigen $(20 \mathrm{mg} / \mathrm{ml})$ were prepared as described by Stanley et al (1972). Antigen wells of $6 \mathrm{~mm}$ and $2 \mathrm{~mm}$ diameter were separated by $6 \mathrm{~mm}$ from a central serum well of $14 \mathrm{~mm}$ diameter. The smaller antigen wells were calculated to give a volume ratio about one-tenth of the larger to assist in the detection of antibodies in weakly reacting sera (Murray, Buckley, and Turner, 1969) or reactions that might be masked by excess mannan (Pepys, Faux, Longbottom, McCarthy, and Hargreaves, 1968). The plates were incubated at $30^{\circ} \mathrm{C}$ for five days. The agar was washed for three days in changes of borate buffer, dried, and stained with Coomassie Brilliant Blue $\mathrm{R}$ (5g dissolved in $450 \mathrm{ml}$ methanol, $450 \mathrm{ml}$ distilled water, and $100 \mathrm{ml}$ glacial acetic acid). Differentiation was in the dye solvent. A positive precipitin result was recorded from the stained agar if a band was produced to any of the three antigens.

\section{Results}

\section{MICROBIOLOGICAL FINDINGS}

Two hundred and ten yeast isolates were cultured from the initial specimens. Ninety-five per cent (190) of the 200 women harboured C. albicans. C. albicans occurred in association with $C$. krusei (1), with Saccharomyces cerevisiae (1), with Torulopsis glabrata (6), and with other Torulopsis species (2). In nine women the only yeast isolated was $T$. glabrata (6), or $S$. cerevisiae (2), or C. stellatoidea (1). Neisseria gonorrhoeae was isolated with Trichomonas vaginalis and $C$. parapsilosis from one patient. $T$. vaginalis was observed simultaneously with yeasts in seven women $(3.5 \%)$; in six of these the associated yeast was $C$. albicans (3\%) (table I). T. vaginalis was seen in specimens from a further six of 96 women whose vaginal flora was subsequently studied.

\section{CLINICAL FINDINGS}

The incidence of signs and symptoms relevant to vulvovaginitis in this group of women is given in

\begin{tabular}{lc}
\hline & No. \\
\hline Vaginitis & $68(34.0 \%)$ \\
Vulvitis & $0(0.0 \%)$ \\
Vulvovaginitis & $5(2.5 \%)$ \\
Plaques & $3(1.5 \%)$ \\
Irritation & $80(40.0 \%)$ \\
Discharge & $163(81.5 \%)$ \\
Diabetes & $4(2.0 \%)$ \\
Glycosuria & $12(6.0 \%)$ \\
\hline
\end{tabular}

Table II Relevant recorded clinical data in 200

symptomatic pregnant women harbouring yeasts in the vagina

table II. In 75 patients the clinicopathological criteria of Carroll et al (1973) were used to establish the diagnosis of $C$. albicans vaginitis. These are the presence of vaginal thrush plaques, irrespective of isolation of the thrush fungus, and signs of vaginitis, with or without concomitant vulvitis, coupled with isolation of C. albicans. Discharge and irritation are ignored as being of no probative value. These criteria were supplemented, and women with diabetes, from whom $C$. albicans was isolated, were regarded as having candida vaginitis (Hesseltine, 1933). The frequency of observation of Trichomonas vaginalis relative to candida, throughout the pregnancy, together with the response to specific therapy, was taken into account when deciding whether vaginitis was primarily mycotic or trichomonadic. Of the remaining women, prompt response to antifungal therapy, together with isolation of $C$. albicans, was regarded as indicative that the vaginitis was probably of mycotic origin (48 patients) and the isolation of C. albicans from 55 of 62 women, for whom no final diagnosis was reached, also indicated probable mycosis.

Thus, in 75 patients the diagnosis of candida vaginitis was established for certain, while in 103, it was probable. Predominantly trichomonadic vaginitis was diagnosed in nine patients; concurrent candida and trichomonadic vaginitis in three; gonorrhoea in one; and no firm aetiological diagnosis in nine.

INCIDENCE OF CANDIDA PRECIPITINS

Ninety-five of the 200 requested sera tested $(47 \cdot 5 \%)$ contained precipitins to at least one of the three antigens tested. The incidence of precipitins in the

\begin{tabular}{lllc}
\hline Total C. albicans Isolated & $\begin{array}{l}\text { C. albicans Isolated } \\
\text { Associated with Other } \\
\text { Yeasts }\end{array}$ & $\begin{array}{l}\text { Yeasts Isolated } \\
\text { Unassociated with } \\
\text { C. albicans }\end{array}$ & $\begin{array}{l}\text { Neisseria gonorrhoeae } \\
\text { Isolated }\end{array}$ \\
\hline 190 & 10 & 10 & $\begin{array}{l}\text { Trichomonas vaginalis } \\
\text { Seen }\end{array}$ \\
\hline
\end{tabular}

Table 1 Principal microbiological findings at first examination (VS) of 200 pregnant women with symptoms and signs of vulvovaginitis harbouring vaginal yeasts 
different clinical groups is shown in table III. Sixtyfour per cent of the 75 women diagnosed on clinicopathological criteria as having $C$. albicans vaginitis, and $42 \%$ of the 48 women with probable $C$. albicans vaginitis, diagnosed on response to antifungal therapy, had precipitating antibodies to $C$. albicans. The three women with mixed candida and trichomonadic vaginitis and $32 \%$ of the remainder had precipitins in their sera.

The analysis of results obtained with each individual antigen is given in table IV. It can be seen that the reactions detected by the pure mannan and cytoplasmic antigens do not differ appreciably in any of the clinical groups. However, tests were not carried out to determine whether the patients' sera were reacting with the mannan or protein components of the cytoplasmic antigen, although certain sera gave multiple bands with the latter. Most reactions were detected with the culture filtrate antigen.

\begin{tabular}{|c|c|c|c|}
\hline $\begin{array}{l}\text { Final Aetiological } \\
\text { Diagnosis of the } \\
\text { Vaginitis }\end{array}$ & No. & $\begin{array}{l}\text { C. albicans } \\
\text { Isolated }\end{array}$ & $\begin{array}{l}\text { Candida Preci- } \\
\text { pitins Present }\end{array}$ \\
\hline C. albicans ${ }^{1}$ & 75 & 75 & $48(64 \%)$ \\
\hline C. albicans ${ }^{2}$ & 48 & 48 & $20(42 \%)$ \\
\hline Other mycotic ${ }^{1}$ & 0 & 0 & 0 \\
\hline Other mycotic & 2 & 0 & 1 \\
\hline $\begin{array}{l}\text { Mixed mycotic and } \\
\text { trichomonadic }\end{array}$ & 3 & 3 & 3 \\
\hline $\begin{array}{l}\text { Predominantly } \\
\text { trichomonadic }\end{array}$ & 9 & 9 & 3 \\
\hline $\begin{array}{l}\text { Gonorrhoea } \\
\text { Not certainly }\end{array}$ & 1 & 0 & 0 \\
\hline established & 62 & 55 & $20(32 \%)$ \\
\hline
\end{tabular}

Table III Incidence of candida precipitins in 200 pregnant women with symptoms or signs of vulvovaginitis and harbouring yeasts in the vagina

Diagnosis based on clinicopathological criteria of Carroll et al (1973). ${ }^{2}$ Cases diagnosed on favourable response to antifungal therapy.
As previously described by Stanley et al (1972), noọ single antigen, or single concentration of an antigen detects all positive reactions. Until the diagnostic sig $\underset{-\frac{5}{5}}{+}$ nificance of reactions to particular components of antigenic extracts of $C$. albicans is determined we $\stackrel{\bar{\sigma}}{\text {. }}$ recommend the use of all three antigens as an aids to the diagnosis of $C$. albicans vaginitis. Reactions toळ all three antigens appear more frequently in mycoticen and probable mycotic vaginitis than in other clinicalgroups described in this paper and may relate to weight or chronicity of infection or overgrowth of $\vec{\omega}$ the fungus.

Sera from 50 of the 200 women, stored since the routine antenatal booking tests had been made, were also examined, and the results of the twoserological examinations were compared. Thirty-twog per cent of sera contained candida precipitins ato booking, and $52 \%$ contained precipitins on serological examination following the first isolation ofe yeasts from the vagina. In $28 \%$ precipitins weres present in both the booking and in the requestedo serum. Thus, $24 \%$ of patients had acquired candida precipitins during pregnancy, Half of the womence who had acquired precipitins had had symptoms at $\$$ booking, and in a quarter of them, the predictedo clinical diagnosis had been mycotic vaginitis.

Finally, sera were obtained from seven of the babies with thrush born to the 200 women, but noneg contained precipitating antibodies to $C$. albicans.

\section{Discussion}

Stanley et al (1972) reviewed the literature pertaining to candida precipitins, commenting that they believect that theirs was the first study of the distribution and? probable significance of candida precipitins in 3 pregnant women. They commented on the difficultiesi

\begin{tabular}{|c|c|c|c|c|c|c|c|c|c|c|c|}
\hline \multirow{2}{*}{$\begin{array}{l}\text { Final Aetiological Diagnosis } \\
\text { of the Vaginitis }\end{array}$} & \multicolumn{11}{|c|}{ Positive Reactions to Antigens of C. albicans } \\
\hline & $M$ & $S$ & $C F$ & $M+S \div C F$ & MOnly & S Only & CF Only & $\begin{array}{l}M+S \\
O n l y\end{array}$ & $\begin{array}{l}M+C F \\
\text { Only }\end{array}$ & $\begin{array}{l}S+C F \\
\text { Only }\end{array}$ & Total +ve \\
\hline C. albicans ${ }^{1}$ (75) & 29 & 28 & 42 & 21 & 3 & 0 & 15 & 3 & 2 & 4 & 48 \\
\hline C. albicans ${ }^{2}(48)$ & 11 & 14 & 17 & 8 & 1 & 2 & 3 & 0 & 2 & 4 & 20 \\
\hline Other mycotic ${ }^{1}(0)$ & 0 & 0 & 0 & 0 & 0 & 0 & 0 & 0 & 0 & 0 & 0 \\
\hline Other mycotic ${ }^{2}(2)$ & 1 & 1 & 1 & 1 & 0 & 0 & 0 & 0 & 0 & 0 & 1 \\
\hline $\begin{array}{l}\text { Mixed mycotic and } \\
\text { trichomonadic (3) }\end{array}$ & 1 & 1 & 3 & 1 & 0 & 0 & 2 & 0 & 0 & 0 & 3 \\
\hline Predominantly & & & & & & & & & & & \\
\hline trichomonadic (9) & 2 & 2 & 3 & 2 & 0 & 0 & 1 & 0 & 0 & 0 & 3 \\
\hline $\begin{array}{l}\text { Gonorrhoea (1) } \\
\text { Not certainly }\end{array}$ & 0 & 0 & 0 & 0 & 0 & 0 & 0 & 0 & 0 & 0 & 0 \\
\hline established (62) & 13 & 13 & 17 & 9 & 2 & 0 & 4 & 1 & 1 & 3 & 20 \\
\hline Total + ve & 57 & 59 & 83 & 42 & 6 & 2 & 25 & 4 & 5 & 11 & 95 \\
\hline
\end{tabular}

Table IV Incidence of candida precipitins to three antigens of $\mathrm{C}$. albicans in 200 selected pregnant women

1,2 See table III

$\mathbf{M}=$ mannan; $\mathbf{S}=$ cytoplasmic; $\mathbf{C F}=$ culture filtrate 
of achieving an accurate aetiological diagnosis of vaginitis using uncritical clinical and laboratory criteria, and they considered that a serological test might prove of value in the diagnosis of pregnancy thrush. They showed that the number of patients from whom C. albicans is isolated, in the absence of signs of plaque formation, or of vaginitis, is small (15\%) but not negligible (Carroll et al, 1973), and, conversely, that $84 \%$ of women from whom $C$. albicans is isolated during pregnancy have signs of vaginitis. The patients who were the subjects of the present study were selected because, as a group harbouring yeasts, they were likely to have a high incidence of $C$. albicans vaginitis, and thus to afford a large number of sera suitable for the assessment of the specificity and sensitivity of precipitin tests in the diagnosis of mycotic vaginitis.

The identity of the vaginal yeasts from the population selected did not differ from that previously noted in other studies from our hospital, and the predominating fungus was the pathogen $C$. albicans which was isolated from $95 \%$ of the patients.

A high overall incidence $(47.5 \%)$ of precipitating antibodies to antigens of $C$. albicans was found in the selected women, all of whom had symptoms ascribed to vaginitis, and harboured yeasts in the vagina. This is significantly higher than the $18 \%$ recorded for an unselected pregnant population (Stanley et al, 1972). Applying clinicopathological criteria previously enunciated (Carroll et al, 1973) to validate the diagnosis, candida precipitins occurred in $64 \%$ of 75 women with undoubted candida vaginitis, and in $42 \%$ of 48 women, whose response to therapy suggested specificfungal vaginitis. C.albicans was isolated from 55 of a further group of 62 patients and theincidence of precipitins, although lower $(32 \%)$ than in women with undoubted candida vaginitis, was still almost double that occurring in an unselected population, suggesting that the aetiology of the vaginitis was mycotic. Stanley et al (1972) showed that the presence of precipitins was significantly associated with acute, recurrent, or relapsing candida vaginitis $(P<0.001)$.

These observations encourage us to propose that serological examination of pregnant women for the presence of candida precipitins may prove a useful test for candida vaginitis, and an adjunct to culture. It may also be of use as a screening procedure for early detection of candida vaginitis. With the methods and criteria of disease that we have used, its sensitivity, according to the formula (Wilson and Jungner, 1968):
Sensitivity $=$

Diseased persons with positive test

All persons in population with disease is $64 \%$.

Its specificity, according to the formula: Specificity $=$

Non-diseased persons with negative test

All persons in population without disease

is $87 \%$, this figure being based on studies on an unselected population (Stanley et al, 1972).

Thus, the 'false negative' rate is of the order of $36 \%$ and the 'false positive' rate of the order of $13 \%$. The test systems used are, therefore, valid, since they separate those who have candidosis from those who do not.

There is every hope that the sensitivity of the serological test can be improved, by variation of the antigens used, and the techniques employed. For example, it may be possible to elaborate more highly specific antigens, or to improve sensitivity without loss of specificity by concentrating the serum. In this study, as before, we have made no attempt to correlate positive findings with the presence of other superficial candida mycoses, and the 'false' positives may relate to candidosis elsewhere. Meanwhile, the test methods described may still prove useful, if serological examination encourages early and more accurate diagnosis and prompt treatment of candida vaginitis during pregnancy.

\section{References}

Carroll, C. J., Hurley, R., and Stanley, V. C. (1973). Criteria for diagnosis of candida vulvovaginitis in pregnant women. J. Obstet. Gynaec. Brit. Cwlth, 80, 258-263.

Hesseltine, H. C. (1933). Diabetic or mycotic vulvovaginitis. J. Amer. med. Ass., 100, 177-178.

Hurley, R., Leask, B. G. S., Faktor, J. A., and de Fonseka, C. I. (1973). Incidence and distribution of yeast species and Trichomonas vaginalis in the vagina of pregnant women. J. Obstet. Gynaec. Brit. Cwlth, 80, 252-257.

Merritt, A. E., and Hurley, R. (1972). Evaluation of sporulation medin for yeasts obtained from pathological material. J. Med. Microbiol., 5, 21-30.

Murray, I. G., Buckley, H. R., and Turner, G. C. (1969). Serological evidence of candida infection after open-heart surgery. J. med. Microbiol., 2, 463-469.

Pepys, J., Faux, J. A., Longbottom, J. L., McCarthy, D. S., and Hargreave, F. E. (1968). Candida albicans precipitins in respiratory disease in man. J. Allergy, 41, 305-318.

Stanley, V. C., Hurley, R., and Carroll, C. J. (1972). Distribution and significance of candida precipitins in sera from pregnant women. J. med. Microbiol., 5, 313-320.

Wilson, J. M. G., and Jungner, G. (1968). Principles and Practice of Screening for Disease, (WHO Public Health Papers, no. 34) p. 22. World Health Organization, Geneva. 